\title{
Fethiye Yöresinde Yetiştirilen Gökkuşağı Alabalıklarının (Oncorhynchus mykiss, Walbaum 1792) Doğal Radyoaktivite Düzeyleri
}

\author{
Süleyman Fatih ÖZMEN¹D, Mesut YILMAZ ${ }^{2 *}$ \\ ${ }^{1}$ Akdeniz Üniversitesi Teknik Bilimler MYO, Elektrik ve Enerji Bölümü, 07058 Antalya- Türkiye \\ ${ }^{2}$ Akdeniz Üniversitesi Su Ürünleri Fakültesi, Su Ürünleri Yetiştiriciliği Bölümü, 07058 Antalya-Türkiye
}

*Sorumlu Yazar: myilmaz@akdeniz.edu.tr

Araștırma Makalesi

Geliş 07 Mayıs 2019; Kabul 27 Eylül 2019; Basım 15 Aralık 2019.

Alıntılama: Özmen, S. F., \& Yılmaz, M. (2019). Fethiye yöresinde yetiştirilen gökkuşağı alabalıklarının (Oncorhynchus mykiss, Walbaum 1792) doğal radyoaktivite düzeyleri. Acta Aquatica Turcica, 15(4), 517-523. https://doi.org/10.22392/actaquatr.561514

\section{Özet}

Bu çalıșmada Fethiye yöresinde yetiștirilen gökkuşağı alabalıklarının farklı dokularındaki doğal radyonüklit $\left({ }^{226} \mathrm{Ra},{ }^{232} \mathrm{Th}\right.$ $\mathrm{ve}^{40} \mathrm{~K}$ ) konsantrasyonları belirlenmiştir. Bu amaçla 4 farklı çiftlikten yaklaşık aynı boylarda olan porsiyonluk balıklar alınarak solungaç, karaciğer, deri ve kas dokuları ayrılmıştır. İşletmelerin kullandığı porsiyonluk balık yemleri de örneklenmiştir. Numunelerin yüksek çözünürlüklü germanyum dedektörü ile gama spektrometrik ölçümleri gerçekleştirilmiş ve radyolojik risk faktörleri değerlendirilmiştir. Alabalık örneklerinin yenilebilen kısımlarında ${ }^{226} \mathrm{Ra}$ aktivitesinin $1,47 \pm 0,14-8,26 \pm 0,78 \mathrm{~Bq} \mathrm{~kg}^{-}$ ${ }^{1},{ }^{232} \mathrm{Th}$ aktivitesinin ÖSA-3.38 $\pm 0.30 \mathrm{~Bq} \mathrm{~kg}{ }^{-1}$ ve ${ }^{40} \mathrm{~K}$ aktivitesinin $54,94 \pm 2,23-140,86 \pm 5,82 \mathrm{~Bq} \mathrm{~kg}^{-1}$ aralığında değiştiği gözlenmiş̧tir. Örneklerin radyum eşdeğer aktivitesi ve yıllık etkin dozu sırasıyla 6,45-23,94 Bq kg ${ }^{-1}$ ve $1,87-4,80 \mu \mathrm{Sv} \mathrm{y}^{-1}$ olarak hesaplanmıştır. Elde edilen bulgular balık yetiştiriciliği için referans oluşturması bakımından önemlidir.

Anahtar kelimeler: Gökkuşağı alabalığı, yetiştiricilik, doğal radyoaktivite, HPGe, Oncorhynchus mykiss.

\section{Natural Radioactivity Levels of Rainbow Trout (Oncorhynchus mykiss, Walbaum 1792) Grown in Fethiye Region}

\begin{abstract}
In this study, natural radionuclide $\left({ }^{226} \mathrm{Ra},{ }^{232} \mathrm{Th}\right.$ and $\left.{ }^{40} \mathrm{~K}\right)$ concentrations were determined in different tissues of rainbow trout grown in Fethiye region. For this purpose, approximately the same size of portioned fish were taken from four different farms and then gill, liver, skin and muscle tissues were separated. Portion fish feeds used by enterprises are also exemplified. Gamma spectrometric measurements were performed with high purity germanium detector and radiological risk factors were evaluated. It was observed that ${ }^{226} \mathrm{Ra}$ activity in the edible parts of trout samples varied between $1.47 \pm 0.14-8.26 \pm 0.78 \mathrm{~Bq} \mathrm{~kg}^{-1}$, ${ }^{232} \mathrm{Th}$ activity varied between BDL-3.38 $\pm 0.30 \mathrm{~Bq} \mathrm{~kg}^{-1}$ and ${ }^{40} \mathrm{~K}$ activity in the range of $54.94 \pm 2.23-140.86 \pm 5.82 \mathrm{~Bq} \mathrm{~kg}^{-1}$. The radium equivalent activity and annual effective dose of the samples were calculated as $6.45-23.94 \mathrm{~Bq} \mathrm{~kg}^{-1}$ and $1.87-4.80 \mu \mathrm{Sv}$ year ${ }^{-1}$, respectively. The findings are important in terms of forming a reference for fish farming.
\end{abstract}

Keywords: Rainbow trout, aquaculture, natural radioactivity, HPGe, Oncorhynchus mykiss.

\section{GIRIŞ}

Radyasyon doğal ortamın bir parçasıdır. Radyasyonun kaynağı kozmik ışınlar ile toprakta, suda ve havada bulunan radyonüklitlerdir. En yaygın olarak doğada bulunan doğal radyonüklitler uranyum-238 $\left({ }^{238} \mathrm{U}\right)$, toryum-232 $\left({ }^{232} \mathrm{Th}\right)$, potasyum-40 $\left({ }^{40} \mathrm{~K}\right)$ ile ${ }^{238} \mathrm{U}$ ve ${ }^{232} \mathrm{Th}$ 'nin bozunum ürünleridir (Cinelli vd., 2019). Ayrica, endüstriyel ve sivil ya da askeri nükleer operasyonlar gibi antropojenik aktiviteler de ortama radyonüklit bırakabilirler (Ojovan ve Lee, 2014). Radyonüklitlerin ortamdaki konsantrasyonu, yerel jeoloji, iklim ve tarım uygulamaları gibi doğal ve beşeri faktörlere bağlı olarak değişir (Saleh vd., 2007; Ojovan ve Lee, 2014). Ortamda bulunan radyonüklitler ekosistemler içinde ve ekosistemler arasında sürekli dolaşım halindedir. Ortamdan bitkiler tarafından alınan bu elementler bitki bünyesinde tutulur ve biriktirilir. Benzer şekilde hayvanlar tarafindan solunum ve beslenme yoluyla alınan radyonüklitler organizmada biriktirilirler (Stricht ve Kirchmann, 2001). Besin zinciri yoluyla radyonüklitler bir üst trofik düzeye aktarılırlar (IEAE, 2004). 
İnsan popülasyonunun zaman içinde artan hayvansal protein talebinin karşılanmasında su ürünleri yetiştiriciliği önemli bir yer tutmaktadır. Global su ürünleri üretimi 2016 yılında 110 milyon ton olarak gerçekleşmiştir (FAO, 2018). Türkiye'de ise aynı yıl su ürünleri yetiştiriciliği yoluyla 253395 ton üretim gerçekleştirilmiştir (TÜiK, 2019). TÜİK 2019 verilerine göre içsu balıkları üretimi yaklaş1k 104010 tondur. Ülkemizde en fazla yetiştiriciliği yapılan tatlısu balık türü ise 101761 ton üretim miktarı ile gökkuşağı alabalığıdır (Oncorhynchus mykiss).

Ülkemizde kişi başına düşen su ürünleri tüketimi yıllık 5,5 kg olup (BSGM, 2019), bu kaynaktan insanlara aktarılan radyonüklit yükünün bilinmesi, insan sağlığına olası etkisinin değerlendirilmesi bakımından önemlidir. Ayrıca su ürünleri yetiştiricilik çiftlikleri üretim kalitesini arttırabilmek için gerekli tedbirleri alabileceklerdir. Böylelikle üretim kalitesi yükseltilip uluslararası arenada rekabet gücünün arttırılmasına katkı sağlanacaktır.

Sunulan çalışmada Fethiye yöresinde faaliyet gösteren çiftliklerde yetiştirilen, ihraç edilen ve iç pazarda önemli bir protein kaynağı olarak tüketilen gökkuşağı alabalıklarının farklı dokuları ile balık yemlerindeki radyonüklit yükleri araştırılmıştır. Bu radyonüklitlerden kaynaklanan radyolojik riskler değerlendirilmiştir.

\section{MATERYAL ve YÖNTEM}

\section{Örnekleme ve numunelerin hazırlanması}

Fethiye yöresinde (Şekil 1) faaliyet gösteren 4 gökkuşağı alabalığı üretim çiftliğinden porsiyonluk balık hasatı sonrasında numuneler (her işletmeden rasgele 6-8 birey olacak şekilde) ölü olarak alınmıştır. Her işletmeye ait su sıcaklık ve pH değerleri kaydedilmiştir (Tablo 1). Ayrıca herbir çiftlikten porsiyonluk balıkların beslenmesinde kullanılan 1'er kg yem örneklenmiştir. Tedarik edilen numuneler ağzı sızdırmaz poşetlere konulup etiketlenerek Akdeniz Üniversitesi Su Ürünleri Fakültesi Yetiştiricilik Laboratuarına buzla soğutulmuş kutuda taşınmıştır.

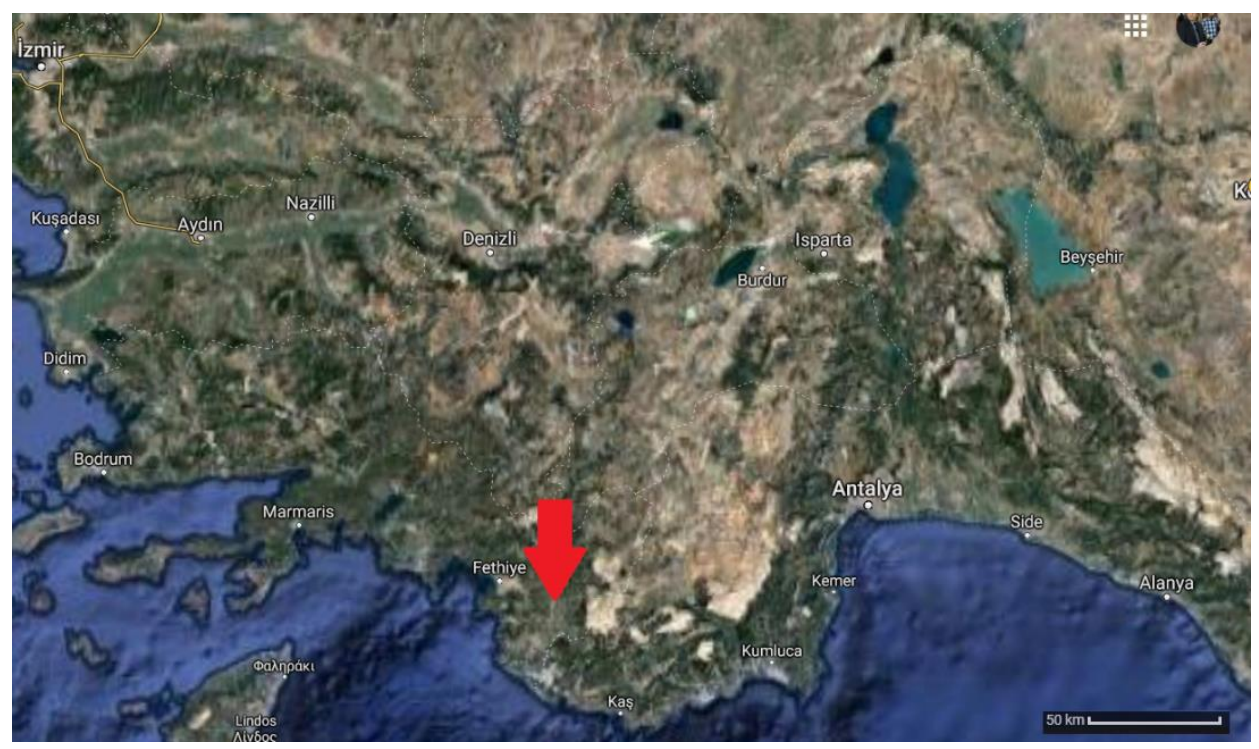

Şekil 1. Çalışma bölgesi

Laboratuvarda öğütülüp homojenize edilen yem örnekleri 2 mm'lik elekten geçirilerek 150cc'lik silindirik kaplara doldurulmuştur. Balık numuneleri laboratuvarda distile su ile yıkanmış ve çatal boyağırlık ölçümleri yapılarak kayda geçirilmiştir (Tablo 1). Daha sonra derisiz filetoları çıkartılmış, organ ve dokuları ayrılmıştır. Filetolar ile solungaç, karaciğer ve deri örnekleri kıyılarak ayrı ayrı 150cc'lik silindirik kaplara doldurulup tartılarak etiketlenmiştir. Analizler yapılana kadar $-20^{\circ} \mathrm{C}$ de saklanmıştır. Örneklerin ağızları gaz sızdırmaz parafilm ile sıkıca kapatılarak ${ }^{226} \mathrm{Ra}-{ }^{222} \mathrm{Rn}$ arasında radyoaktif dengenin oluşması ve Compton bölgesinin kararlı hale gelmesi için (7x3,86gün) yaklaşık 30 gün süreyle bekletilmiştir (Yaprak ve Aslani, 2010). 
Tablo 1. Gökkuşağı alabalıklarının biyometrik ölçümleri* ve su parametreleri

\begin{tabular}{ccccc}
\hline \hline İşletme No & Ăğırlık (g) & Boy $(\mathbf{c m})$ & $\begin{array}{c}\text { Su sıcaklı̆̆ı } \\
\left(\mathbf{C}^{\mathbf{0}}\right)\end{array}$ & pH \\
\hline 1 & $204,00 \pm 7,48$ & $24,44 \pm 0,42$ & 14,2 & 7,76 \\
2 & $202,40 \pm 6,91$ & $25,30 \pm 0,30$ & 12,4 & 7,97 \\
3 & $176,20 \pm 3,25$ & $24,84 \pm 0,37$ & 13,4 & 7,95 \\
4 & $174,60 \pm 3,96$ & $25,00 \pm 0,27$ & 7,8 & 8,62 \\
\hline \hline
\end{tabular}

* Ortalama \pm Standart Hata

\section{Radyonüklit analizi}

HPGe gama spektrometre sistemi: İncelenen materyallerin gamma spektroskopik ölçümleri A.Ü. Fen Fakültesi Fizik Bölümü Gama Spektroskopi Laboratuarında bulunan p-tipi, koaksiyel, elektrik soğutmalı, bağıl verimi \%40 ve ${ }^{57} \mathrm{Co}$ için $122 \mathrm{keV}$ 'de $768 \mathrm{eV}$ FWHM ve ${ }^{60} \mathrm{Co}$ için $1332 \mathrm{keV}$ 'de 1.85 keV FWHM değerlerine sahip AMETEK-ORTEC, GEM40P4 model yüksek saflıkta Germanyum dedektörü ile MAESTRO32 yazılımı kullanılarak gerçekleştirilmiştir. Çalışmada kullanılan HPGe gama spektrometre sisteminin enerji kalibrasyonu, enerjileri $47-1836 \mathrm{keV}$ arasında değişen radyoizotoplar içeren, örneklerle aynı geometrideki karma kaynak ile yapılmıştır. Ölçüm sistemi hakkında detaylı bilgi Özmen vd. $(2013,2014)$ tarafindan verilmiştir.

Spektrum analizi: Tüm numuneler dedektörün penceresine yerleştirilerek $86400 \mathrm{~s}$ boyunca sayılmıştır. Art ortam sayımı, numunelerin ölçümünden önce ve sonra aynı koşullar altında boş bir numune kabı ile elde edilmiştir. Örneklerin gama spektrumlarda ${ }^{226} \mathrm{Ra}$ aktivite konsantrasyonları ${ }^{238} \mathrm{U}$ bozunum serilerindeki ürün radyonüklitlerden yayımlanan ${ }^{214} \mathrm{~Pb} ; 352 \mathrm{keV}$ ve ${ }^{214} \mathrm{Bi} ; 609 \mathrm{keV}$ enerjili pikler, ${ }^{232} \mathrm{Th}$ aktivite konsantrasyonları ${ }^{232} \mathrm{Th}$ bozunum serilerindeki ürün radyonüklitlerden yayımlanan, ${ }^{228} \mathrm{Ac} ; 911 \mathrm{keV},{ }^{208} \mathrm{Tl} ; 583$ ve $2615 \mathrm{keV}$ enerjili pikler, ${ }^{40} \mathrm{~K}$ aktivite konsantrasyonları ise $1461 \mathrm{keV}$ enerjili pik kullanılılarak belirlenmiştir. 4 nolu işletmeden alınan kas numunesine ait spektrum örneği Şekil 2'de verilmiştir.

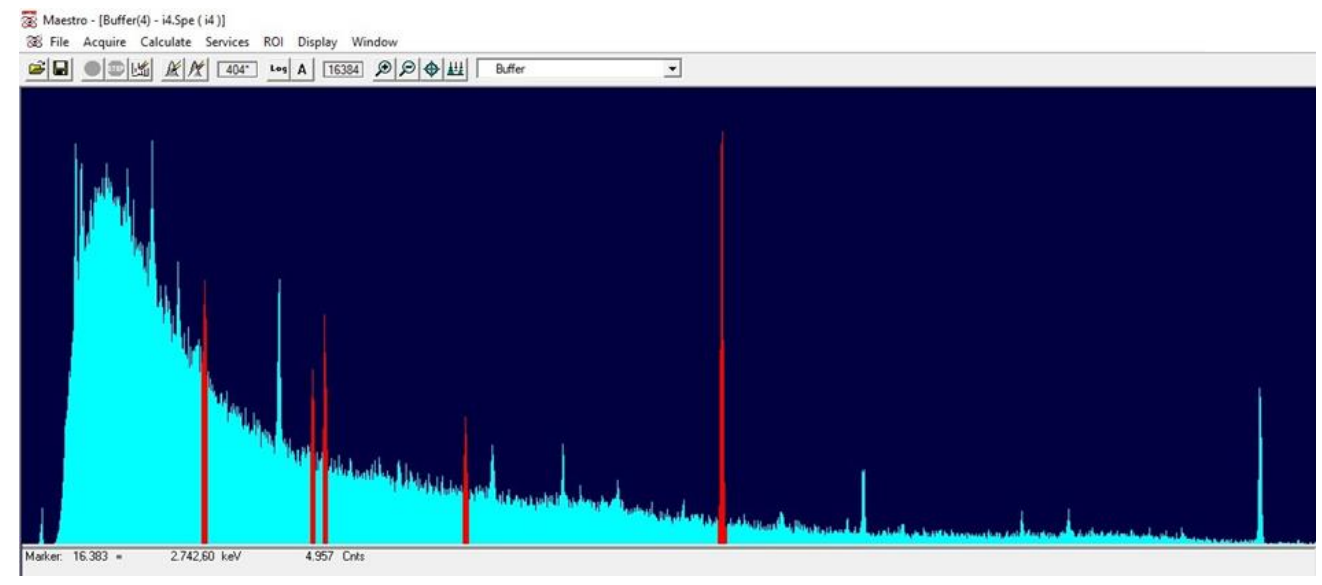

Şekil 2. İşletme 4'ten alınan kas numunesine ait spektrum

Radyonüklit aktivite konsantrasyonları aşağıdaki denklem kullanılarak tayin edilmiştir.

$$
A=\frac{N / t}{\varepsilon x I \gamma \times m}
$$

Burada A; ilgilenilen radyonüklitin aktivitesi $\left(\mathrm{Bq} \mathrm{kg}^{-1}\right), \mathrm{N}$; ilgilenilen enerjideki toplam net sayım (Pik alanları, toplam alandan art-ortam alanı çıkarılarak elde edilmiştir), t; sayım süresi (saniye), $\varepsilon$; HPGe dedektörünün ilgilenilen gama enerjisindeki verimi, I ; gama ışınının bolluğu ve m; örnek kütlesidir. 


\section{Radyolojik risk parametreleri}

İnsanların balık tüketiminden dolayı maruz kaldıkları radyolojik tehlikeleri değerlendirmek için, radyum eşdeğer aktivitesi $\left(\mathrm{Ra}_{\mathrm{e}}\right)$, yıllık etkin doz (YED) ve iç zarar indeksi $\left(\mathrm{H}_{\text {in }}\right)$ parametreleri hesaplanmıştır.

Radyum Eşdeğer Aktivitesi $\left(\mathrm{Ra}_{\mathrm{ess}}\right):{ }^{238} \mathrm{U},{ }^{232} \mathrm{Th}$ ve ${ }^{40} \mathrm{~K}$ in çevrede dağılımı birbirlerinden farklıdır. Farklı miktarlardaki bu spesifik aktivitelerinden radyasyona maruz kalmayı standartlaştırmak için radyum eşdeğer aktivitesi $\left(\mathrm{Ra}_{\text {eş}}\right)$ aşağıdaki ifade ile tanımlanmaktadır (Beretka ve Mathew, 1985).

$$
R a_{e s}=C_{U}+1,43 C_{T h}+0,07 C_{K}
$$

Burada $\mathrm{C}_{\mathrm{U}}, \mathrm{C}_{\mathrm{Th}}$ ve $\mathrm{C}_{\mathrm{K}}$ sirasiyla ${ }^{238} \mathrm{U},{ }^{232} \mathrm{Th}$ ve ${ }^{40} \mathrm{~K}$ '1n $\mathrm{Bq} \mathrm{kg}-1$ olarak spesifik aktiviteleridir.

Yıllık Etkin Doz (YED): Vücuttaki radyonüklit alımı ile ilişkili radyasyona bağlı sağlık etkilerinin tahminleri, radyonüklitlerin oluşturduğu toplam doz ile orantılıdır. Gıdalardan alınan radyasyon dozları, gıda maddelerinin içerdiği radyonüklit aktiviteleri ve bu gıdaların yıllık tüketim miktarı ile doğru orantılıdır. Gıdalarda ölçülen radyonüklitlerin aktivite konsantrasyonlarından yılık etkin dozu hesaplamak için Uluslararası Radyolojik Koruma Komisyonu (ICRP, 2012) tarafından önerilen doz dönüşüm katsayıları kullanılır.

$$
Y E D=\sum_{i}\left(D_{i} C_{i}\right) * U
$$

Burada $\mathrm{D}_{\mathrm{i}}$ ilgili radyonüklitin doz dönüşüm katsayısı $\left(\mathrm{Sv} \mathrm{Bq}^{-1}\right)$, U ilgili balığın yıllık kişi başı tüketim miktarı $\left(\mathrm{kg} \mathrm{y}^{-1}\right), \mathrm{C}_{\mathrm{i}}$ ise ilgili radyonüklitin $\mathrm{Bq} \mathrm{kg}^{-1}$ olarak spesifik aktiviteleridir. BSGM 2018 verilerine göre Türkiye' de kişi başı alabalık tüketimi yıllık 5,5kg, ICRP (2012) tarafından önerilen doz dönüşüm katsayıları ise ${ }^{238} \mathrm{U}\left({ }^{226} \mathrm{Ra}\right)$ için $2,8 \times 10^{-7},{ }^{232} \mathrm{Th}\left({ }^{228} \mathrm{Ac}\right)$ için $4,3 \times 10^{-10} \mathrm{ve}^{40} \mathrm{~K}$ için $6,2 \times 10^{-9} \mathrm{~Sv} \mathrm{~Bq}{ }^{-1}$ dir.

İç Zarar İndeksi $\left(\mathrm{H}_{\text {in }}\right)$ : Radon ve kısa ömürlü bozunum ürünleri solunum organları için tehlikelidir. Radon ve bozunum ürünlerinden kaynaklanan içsel maruz kalma, Krieger (1985) tarafından tanımlanan aşağıdaki denklemde verilen iç zarar indeksi $\left(\mathrm{H}_{\text {in }}\right)$ ile ölçülür;

$$
H_{\text {in }}=C_{U} / 185+C_{T h} / 259+C_{K} / 4810
$$

Burada $\mathrm{C}_{\mathrm{U}}, \mathrm{C}_{\mathrm{Th}}$ ve $\mathrm{C}_{\mathrm{K}}$ sirasiyla ${ }^{238} \mathrm{U},{ }^{232} \mathrm{Th}$ ve ${ }^{40} \mathrm{~K}$ ' $1 \mathrm{n} \mathrm{Bq} \mathrm{kg}{ }^{-1}$ biriminde spesifik aktiviteleridir. Radyasyon zararının önemsiz olabilmesi için $\mathrm{H}_{\text {in }}$ değeri 1'den küçük olmalıdır.

\section{BULGULAR ve TARTIŞMA}

Çalışma kapsamında yöreyi temsil edecek şekilde 4 farklı işletmeden alınan gökkuşağı alabalığ 1 ve yem örneklerinin HPGe gama spektrometre sistemi ile ölçülen ${ }^{226} \mathrm{Ra},{ }^{232} \mathrm{Th}$ ve ${ }^{40} \mathrm{~K}$ radyonüklit aktivite konsantrasyonları Tablo 2'de verilmiştir. Öte yandan, Türkiye'de ve yurt dışında değişik bölgelerde yapılan çalışmalar da karşılaş̧ırılmak üzere Tablo 3'te özetlenmiştir.

4 farklı işletmeden tedarik edilen balık numunelerinin ${ }^{226} \mathrm{Ra}$ aktivitesinin kaslarda 3,29 $\pm 0,27$ ile $8,26 \pm 0,78 \mathrm{~Bq} \mathrm{~kg}^{-1}$ arasında, ${ }^{232} \mathrm{Th}$ aktivitesinin ÖSA- 3,38 $\pm 0,30 \mathrm{~Bq} \mathrm{~kg}^{-1}$ arasında ve ${ }^{40} \mathrm{~K}$ aktivitesinin $102,69 \pm 5,22-140,86 \pm 5,82$ arasında değiştiği tespit edilmiştir. Tablo 2'ye göre kas radyonüklit konsantrasyonları en yüksek olan 1 nolu işletmede yetiştirilen balıkların farklı dokularındaki radyonüklit birikimleri incelendiğinde, ${ }^{226} \mathrm{Ra}$ aktivitesinin solungaçlarda $7,15 \pm 0,67 \mathrm{~Bq} \mathrm{~kg}^{-1}$, deride $7,07 \pm 0,68 \mathrm{~Bq} \mathrm{~kg}^{-}$ ${ }^{1}$, karaciğerde $1,47 \pm 0,14 \mathrm{~Bq} \mathrm{~kg}^{-1}$ olduğu; ${ }^{232} \mathrm{Th}$ aktivitesinin solungaçlarda $3,34 \pm 0,32 \mathrm{~Bq} \mathrm{~kg}^{-1}$, deride $3,04 \pm 0,25 \mathrm{~Bq} \mathrm{~kg}^{-1}$, karaciğerde ölçülebilen değerin altında olduğu; ${ }^{40} \mathrm{~K}$ aktivitesinin ise solungaçlarda $105,94 \pm 4,57 \mathrm{~Bq} \mathrm{~kg}^{-1}$, deride $54,94 \pm 2,23 \mathrm{~Bq} \mathrm{~kg}^{-1}$, karaciğerde $64,65 \pm 2,88 \mathrm{~Bq} \mathrm{~kg}^{-1}$ olduğu tespit edilmiştir. 
Tablo 2. Gökkuşağı alabalığı dokuları ve yemlerinin ${ }^{226} \mathrm{Ra},{ }^{232} \mathrm{Th},{ }^{40} \mathrm{~K}\left(\mathrm{~Bq} \mathrm{~kg}^{-1}\right.$ yaş ağırlık) aktivite konsantrasyonları*

\begin{tabular}{lccccc}
\hline \hline Doku & İşletme no & $\mathbf{N}$ & ${ }^{226} \mathbf{R a}$ & ${ }^{232} \mathbf{T h}$ & ${ }^{\mathbf{2 0} \mathbf{K}}$ \\
\hline & 1 & 8 & $8,26 \pm 0,78$ & $3,38 \pm 0,30$ & $140,86 \pm 5,82$ \\
Kas & 2 & 5 & $5,50 \pm 0,52$ & ÖSA & $102,69 \pm 5,22$ \\
& 3 & 6 & $3,29 \pm 0,27$ & $2,25 \pm 0,19$ & $125,21 \pm 7,02$ \\
Karaciğer & 4 & 7 & $3,46 \pm 0,33$ & ÖSA & $118,08 \pm 7,05$ \\
Deri & 1 & & $1,47 \pm 0,14$ & ÖSA & $64,65 \pm 2,88$ \\
Solungaç & 1 & $7,07 \pm 0,68$ & $3,04 \pm 0,25$ & $54,94 \pm 2,23$ \\
Yem & $1-2-3-4$ & $7,15 \pm 0,67$ & $3,34 \pm 0,32$ & $105,94 \pm 4,57$ \\
ÖSA: Ölçüm sınırının altında, N: numune sayıs1, * Ortalama \pm Standart Hata & ÖSA & $9,54 \pm 0,88$ & $174,98 \pm 8,50$ \\
\hline
\end{tabular}

Buna göre kültür gökkuşağı alabalığı dokularında ${ }^{226} \mathrm{Ra}$ ve ${ }^{232} \mathrm{Th}$ için radyonüklit birikiminin kas $>$ solungaç $>$ deri $>$ karaciğer şeklinde sıralandığ $1,{ }^{40} \mathrm{~K}$ için ise karaciğerde deriye nazaran daha fazla birikimin (kas >solungaç>karaciğer $>$ deri) olduğu görülmektedir.

Balık yemleri yetiştiriciliği yapılan balığın ihtiyacını karşılayacak içerikte birçok yem hammaddesinin bir araya getirilmesi ile elde edilir. Bu durumda rasyona dahil olan hammaddelerin radyonüklit içerikleri elde edilen yemin yükünü de etkiler. Ayrıca üretilen yemin üretim prosesi yem kalitesi üzerine etkilidir. Örnekleme yapılan 4 işletmede aynı firmaya ait yemler kullanıldığ 1 için ölçüm sonuçlarının ortalaması verilmiştir (Tablo 2). İncelenen tüm yem örneklerinde ${ }^{226} \mathrm{Ra}$ aktivitesi ölçülebilen sınırın altında kalmıştır. ${ }^{232} \mathrm{Th}$ ve ${ }^{40} \mathrm{~K}$ aktiviteleri ise sırasıyla ortalama $9,54 \pm 0,88$ ve $174,98 \pm 8,50 \mathrm{~Bq} \mathrm{~kg}^{-1}$ ' dir.

Balıklarda gözlemlenen radyonüklit konsantrasyonları yem ve içinde yaşadığı ortamdan etkilenmektedir (Stricht ve Kirchmann, 2001; IEAE, 2004). Kas dokusunda tespit edilen ${ }^{232} \mathrm{Th}$ ve ${ }^{40} \mathrm{~K}$ aktivitesinin olas1 kaynaklarından birinin yetiştiricilikte kullanılan yem olduğu Tablo 2'de verilen yemlere ait ${ }^{232} \mathrm{Th}$ ve ${ }^{40} \mathrm{~K}$ aktivite konsantrasyonlarından açıkça anlaşılmaktadır. Ancak yemde tespit edilemeyen ${ }^{226} \mathrm{Ra}$ aktivitesinin kasta bulunması çevresel koşulları işaret etmektedir. Kaynağın tespiti yönünde ayrıntılı çalışmalara ihtiyaç vardır.

Tablo 3. Türkiye' de ve diğer ülkelerde balıklar üzerinde yapılan çalışmalar ( $\left.\mathrm{Bq} \mathrm{kg}^{-1}\right)$

\begin{tabular}{lcccl}
\hline \hline Ülke & ${ }^{\mathbf{2 2 6}} \mathbf{~ R a}$ & ${ }^{\mathbf{2 3 2}} \mathbf{T h}$ & ${ }^{\mathbf{4 0}} \mathbf{K}$ & Kaynak \\
\hline Amerika (Mississippi) Çiftlik & 0,41 & 0,89 & 99 & Billa vd., 2016 \\
Amerika (Mississippi) Nehir & 0,47 & 0,97 & 101 & Billa vd., 2016 \\
Bangladeş (Bengal Körfezi) & 1,05 & 0,77 & 61,5 & Ghose vd., 2000 \\
Güney Afrika & 34,6 & 38,7 & - & Faanhof ve Louw 2001 \\
Nijerya (Ado Ekiti) & $17,8 \pm 0,6$ & $3,5 \pm 0,4$ & $533,3 \pm 37,0$ & Fasae ve Isinkaye 2018 \\
Nijerya (Kainji) & 37,2 & 94,8 & 618,2 & Adamu vd., 2013 \\
Nijerya (Nijer Deltası) & 4,5 & 11,0 & 37,4 & Bolaji vd., 2015 \\
Nijerya (Ondo) & $21,4-38,6$ & $40,7-64,4$ & $462-792$ & Ademola ve Ehiedu 2010 \\
Oman Denizi & $0,14-2,66$ & $0,06-4,68$ & $38-570$ & Goddart vd., 2003 \\
Pakistan & 1,30 & 1,0 & 90 & Tahir vd., 2010 \\
Türkiye & 45,6 & ÖSA & 179 & Topcuoglu vd., 2003 \\
Türkiye (Van Gölü) & 0,57 & 0,022 & 319 & Erenturk vd., 2014 \\
Türkiye (Trabzon) & 0,76 & 1,03 & 101,72 & Görür vd., 2012 \\
\hline \hline
\end{tabular}

ÖSA: Ölçüm sınırının altında 
Balık doku ve yem örneklerinin tümünün ${ }^{226} \mathrm{Ra},{ }^{232} \mathrm{Th}$ ve ${ }^{40} \mathrm{~K}$ aktivite konsantrasyonlarının Türkiye ve diğer ülke sonuçlarıyla genel olarak uyumlu, Güney Afrika Nijerya'da (Faanhof ve Louw, 2001; Fasae ve Isinkaye, 2018; Adamu vd., 2013; Ademola ve Ehiedu, 2010) yapılan çalışmalarda raporlanan sonuçların çok altında olduğu gözlenmektedir.

Çalışma kapsamında incelenen alabalık dokuları ile yem örneklerinin ${ }^{226} \mathrm{Ra},{ }^{232} \mathrm{Th}$ ve ${ }^{40} \mathrm{~K}$ aktivite konsantrasyonları kullanılarak [Radyum eşdeğer aktivite $\left(\mathrm{Ra}_{\text {es }}\right)$, İç zarar indeksi $\left(H_{\text {in }}\right)$ ve Yıllık etkin doz (YED)] radyolojik risk parametreleri hesaplanmış ve bulgular Tablo 4'te listelenmiştir.

Tablo 4. Gökkuşağı alabalık dokularının ve yem örneklerinin radyolojik risk parametreleri

\begin{tabular}{|c|c|c|c|c|}
\hline Doku & İşletme no & $\operatorname{Ra}_{\text {eș }}\left(B q \mathbf{k g}^{-1}\right)$ & $\mathbf{H}_{\text {in }}$ & YED $\left(\mu S v y^{-1}\right)$ \\
\hline \multirow{4}{*}{ Kas } & 1 & 23,94 & 0,22 & 4,80 \\
\hline & 2 & 13,40 & 0,17 & 3,50 \\
\hline & 3 & 16,15 & 0,21 & 4,27 \\
\hline & 4 & 12,55 & 0,16 & 4,03 \\
\hline Karaciğer & 1 & 6,45 & 0,23 & 2,20 \\
\hline Deri & 1 & 15,65 & 0,19 & 1,87 \\
\hline Solungaç & 1 & 20,08 & 0,26 & 3,61 \\
\hline Yem & $1-2-3-4$ & 27,12 & 0,07 & 5,97 \\
\hline \multicolumn{2}{|c|}{ Dünya ort. (UNSCEAR, 2000) } & 370 & $\leq 1$ & $\begin{array}{c}200-800 \\
\text { (ortalama 290) }\end{array}$ \\
\hline
\end{tabular}

Doku örnekleri 6,45 (karaciğer) - 23,94 (kas) Bq kg -1 aralığında değişen radyum eşdeğer aktiviteleri üretirken yem örneklerinin ortalama radyum eşdeğer aktivitesi $27,12 \mathrm{~Bq} \mathrm{~kg}-1$ olarak hesaplanmıştır. Benzer şekilde ICRP (2012) dönüşüm faktörleri kullanılarak hesaplanan doku örneklerinin yıllık eşdeğer aktiviteleri 1,87 (deri) - 4,80 (kas) $\mu \mathrm{Sv}$ y -1 arasında değişirken yem örneklerinin ortalama yıllık eşdeğer aktivitesi $5,97 \mu \mathrm{Sv}$ y -1 'dır. Belirlenen radyum eşdeğer aktivitesi ve yıllık etkin doz değerleri UNSCEAR 2000'de önerilen ( $\mathrm{Ra}$ eş 370 Bq kg -1 ve YED $290 \mu \mathrm{Sv}$ y -1 ) değerlerin çok altında yer almaktadır. Ayrıca tüm örneklerin iç zarar indeksi (H in ) değerleri 1'den küçüktür. Bu veriler yörede yetiştirilen gökkuşağı alabalığının tüketilmesinin radyolojik bakımdan insan sağlığı için olumsuz bir etki yaratmayacağını göstermektedir.

\section{SONUÇ}

Sonuç olarak, Fethiye yöresinde yetiştirilen gökkuşağı alabalıklarının yenilebilir kısımlarında gözlenen aktivite konsantrasyonlarının tüketici sağlığı bakımından risk teşkil etmeyecek seviyelerde olduğu ortaya konmuştur. Çiftlik koşullarında yetiştirilen gökkuşağı alabalığı dokularında belirlenen ${ }^{226} \mathrm{Ra},{ }^{232} \mathrm{Th}$ ve ${ }^{40} \mathrm{~K}$ aktivite konsantrasyon değerleri bu alanda literatürdeki eksikliği tamamlamakta ve yetiştiriciliği yapılan diğer türlerle kıyaslanabilir nitelikte bir veri seti oluşturmaktadır. Ayrıca, balık dokularında tespit edilen doğal radyonüklitlerin yetiştiricilik ortamındaki orijinlerinin tespiti ve kalitenin arttırılması yönünde alınabilecek tedbirlerin araştırılacağı çalışmalara ihtiyaç vardır.

Teşekkür : Yazarlar olarak, numunelerin gama spektrometrik ölçümleri için araştırma laboratuarını tahsis eden Akdeniz Üniversitesi Fizik Bölümü Öğretim Üyesi Prof. Dr. İsmail BOZTOSUN'a yardım ve desteklerinden dolayı teşekkürü borç biliriz.

Sunulan çalışmada kullanılan balıklar hasat sonrası ölü olarak örneklendiğinden herhangi bir etikprosedür izlenmemiştir.

\section{KAYNAKLAR}

Adamu, R., Zakari, Y.I., Ahmed, A.Y., Abubakar, S., \& Vatsa, A.M. (2013). Analysis of activity concentrations due to natural radionuclides in the fish of Kainji Lake. Advances in Applied Science Research, 4(4), 283287. 
Ademola, J.A., \& Ehiedu, S.I. (2010). Radiological analysis of ${ }^{40} \mathrm{~K},{ }^{226} \mathrm{Ra}$ and ${ }^{232} \mathrm{Th}$ in fish, Crustacean and sediment samples from fresh and marine water in oil exploration area of ondo state, Nigeria. African Journal of Biomedical Research, 13, 99-106.

Beretka, J., \& Mathew, P.J. (1985). Natural radioactivity of Australian building materials, industrial wastes and by-products. Health Physics, pp.48-87.

Billa, J., Han, F., Didla, S., Yu, H., Dimpah, J., Brempong, O., \& Adzanu, S. (2016). Radioactivity studies on farm raised and wild catfish produced in Mississippi, USA. Journal of Radioanalytical and Nuclear Chemistry, 307(1), 203-210.

Bolaji, B.B., Francis, D.S., \& Ibitoruh, H. (2015). Human health impact of natural and artificial radioactivity levels in the sediments and fish of Bonny estuary, Niger Delta, Nigeria. Challenges, 6, 244-257.

BSGM (Balıkçılık ve Su Ürünleri Genel Müdürlüğ̈̈) (2019, 6 Mayıs). T.C. Tarım ve Orman Bakanlığı su ürünleri istatistikleri. Alındı https://www.tarimorman.gov.tr/sgb/Belgeler/SagMenuVeriler /BSGM.pdf.

Cinelli, G., Tollefsen, T., Bossew, P., Gruber, V., Bogucarskis, K., De Felice, L., \& De Cort, M. (2019). Digital version of the European Atlas of natural radiation. Journal of Environmental Radioactivity, 196, $240-252$.

Erenturk, S., Yusan, S., Turkozu, D.A., Camtakan, Z., Olgen, M.K., Aslani, M.A.A., Aytas, S., \& Isik, M.A. (2014). Spatial distribution and risk assessment of radioactivity and heavy metal levels of sediment, surface water and fish samples from Lake Van, Turkey. Journal of Radioanalytical and Nuclear Chemistry, 300(3), 919-931.

Faanhof, A., \& Louw, I. (2001). The measurement of natural radioactivity in fish and the impact on humans. Journal of Radioanalytical and Nuclear Chemistry, 249, 227-232.

FAO (2018). FAO Fisheries Department, Fishery Information, Data and Statistics Unit. FishStatJ, a tool for fishery statistics analysis, Release: 3.04.5, Universal Software for Fishery Statistical Time Series. Global aquaculture production: Quantity 1950-2016; Value 1950-2016; Global capture production: 1950-2016, 2018-03-16.

Fasae, K.P., \& Isinkaye, M.O. (2018). Radiological risks assessment of 238U, 232Th and 40K in fish feeds and catfish samples from selected fish farms in Ado e Ekiti, Nigeria. Journal of Radiation Research and Applied Sciences, 11, 317-322.

Ghose, S., Alam, M.N., \& Islam, M.N. (2000). Radiation dose estimation from the analysis of radionuclides in marine fish of the Bay of Bengal. Radiation Protection Dosimetry, 87, 287-291.

Goddard, C.C., Mathews, C.P., \& Al Mamry, J. (2003). Baseline radionuclide concentrations in Omani Fish. Marine Pollution Bulletin, 46, 914-917.

Gorur, F.K., Keser, R., Akcay, N., \& Dizman, S. (2012). Radioactivity and heavy metal concentrations of some commercial fish species consumed in the Black Sea Region of Turkey. Chemosphere 87, 356-61.

IAEA (International Atomic Energy Agency) (2004). Sediment distribution coefficients and concentration factors for biota in the marine organisms. IAEA Technical report series, No. 422, Vienna.

ICRP (2012). Compendium of Dose Coefficients based on ICRP Publication 60. ICRP Publication 119, Annual ICRP 41(Suppl.).

Krieger, R. (1985). Radioactivity of construction materials Betonw Fertigtl Technol, 47, 468-473.

Ojovan, M.I., \& Lee, W.E. (2014). Nuclear Waste Types and Sources. In: Ojovan,M.I.,Lee, W.E. (Eds), An Introduction to Nuclear Waste Immobilisation (Second Edition), pp 75-97. Elsevier Ltd. Waltham, USA.

Ozmen, S.F., Boztosun, I., Yavuz, M., \& Tunc, M.R. (2013). Determination of gamma radioactivity levels and associated dose rates of soil samples of the Akkuyu/Mersin using high-resolution gamma-ray spectrometry. Radiation Protection Dosimetry, 158 (4), 461-465.

Ozmen, S.F., Cesur, A., Boztosun, I., \& Yavuz, M. (2014). Distribution of natural and anthropogenic radionuclides in beach sand samples from Mediterranean Coast of Turkey. Radiation Physics and Chemistry, 103, 37-44.

Saleh, I.H., Hafez, A.F., Elanany, N.H., Motaweh, H.A., \& Naim, M.A. (2007). Radiological Study on Soils, Foodstuff and Fertilizers in the Alexandria Region, Egypt. Turkish Journal of Engineering and Environmental Sciences, 31, 9-17.

Stricht, E.V.D., \& Kirchmann, R. (2001). Radioecology, Radioactivity \& Ecosystems. Fortemps, Liège.

Tahir, S., Alaamer, A., Ayub, M. \& Khan, M. (2010). Radiometric analysis of samples of domestic fish species and radiological implications. Health Physics, 98(5), 741-744.

Topcuoglu, S., Karahan, G., Güngor, N., \& Kırbasoglu, C. (2003). Natural and artificial radioactivity in Emendere thermal spring area in Western Anatolia. Journal of Radioanalytical and Nuclear Chemistry, 256(3), 395398.

TÜİK (2019, 6 Mayıs). Su ürünleri istatistikleri. Alındı https://biruni.tuik.gov.tr/medas/?kn=97\&locale=tr.

UNSCEAR (2000). Sources and effects of ionizing radiation. Report to General Assembly, with Scientific Annexes. United Nations Scientific Committee on the Effect of Atomic Radiation.

Yaprak, G., \& Aslani, M.A.A. (2010). External dose-rates for natural gamma emitters in soils from an agricultural land in West Anatolia. Journal of Radioanalytical and Nuclear Chemistry, 283, 279-287. 